\title{
Impact of Exposure of Chemical Fumes on Blood Pressure and Peak Expiratory Flow Rate in Industrial Workers of Faisalabad
}

\author{
Shireen Jawed ${ }^{1}$, Benash Altaf ${ }^{2}$, Qaisar Sohail ${ }^{3}$, Noor-i-Kiran Naeem ${ }^{4}$, Farah Amir Ali ${ }^{5}$ \\ Associate Professor, Department of Physiology, Aziz Fatimah Medical and Dental College Faisalabad ${ }^{1}$ \\ Assistant Professor, Department of Physiology, Aziz Fatimah Medical and Dental College, Faisalabad ${ }^{2}$ \\ Statistician, Aziz Fatimah Medical and Dental College, Faisalabad ${ }^{3}$ \\ Assistant Professor, Medical Education Department, Aziz Fatimah Medical and Dental College, Faisalabad ${ }^{4}$ \\ Professor, Department of Physiology, Aziz Fatimah Medical and Dental College, Faisalabad ${ }^{5}$
}

\section{ABSTRACT}

Doi: doi.org/10.53685/jshmdc.v2i1.9

Objectives: 1 . To determine the impact of duration of exposure to industrial chemical fumes on Peak Expiratory Flow Rate (PEFR) and blood pressure of the industrial workers. 2. To find out the association between changes in blood pressure and PEFR due to exposure to industrial chemical fumes in these subjects. Methods: This cross-sectional study was performed at Aziz Fatimah Medical and Dental College, Faisalabad. The study participants were 151 males working in the chemical industries. The study was approved by institutional ethical committee and informed consent was taken from the participants. Free camp was arranged for three days in September 2020 in the industrial area of Faisalabad. Thorough history of exposure to chemicals was taken using structured proforma. PEFR values were recorded using Wrights handheld peak flow meter. Blood pressure was taken by auscultatory method using mercury sphygmomanometer. Data was analyzed using SPSS version 22.

Results: Systolic and diastolic blood pressures were significantly raised with increase in duration of exposure. PEFR levels were significantly declined with increase in duration of exposure to chemicals. Significant negative association was noted between diastolic blood pressure and PEFR ( $p$ value $=0.003$ ). Negative correlation was observed between PEFR and systolic Blood pressure, however it was not statistically significant $(\mathrm{p}$ value $=0.92)$.

Conclusions: PEFR decreased while Systolic and diastolic blood pressures increased significantly with increase in the duration of exposure to chemicals. There was a significant negative correlation between PEFR and diastolic blood pressure while there was no association between PEFR and systolic blood pressure.

Key Words: Peak expiratory flow rate, systolic blood pressure, diastolic blood pressure, air pollution, environment exposure, industrial area.

\author{
Corresponding Author: \\ Dr. Shireen Jawed \\ Associate Professor \\ Department of Physiology \\ Aziz Fatimah Medical and Dental College, \\ Faisalabad \\ Email address: drshireenjawed@gmail.com \\ Received 05.05.21, Revised 12.06.21, \\ Accepted 13.06.21
}

\section{INTRODUCTION}

Air pollution and global warming are continuously on the rise due to modernization, industrialization and increased number of vehicles on the road across the world ${ }^{1}$. Exposure to noxious gases, chemicals and air born particulate matter (PM) emitted from the industries are adversely affecting the human health leading to serious health crisis. 
PM is a complex mixture of toxic substances including element carbon, polycyclic hydrocarbons, organic carbon, other solid and liquid compounds that remain suspended in the atmosphere. PM has been proved to be harmful and injurious to health ${ }^{2}$.

Literatures shows that exposure to a high concentration of air pollutants is associated with impaired pulmonary functions ${ }^{1-3}$. Fine and ultrafine particulate matter in air pollution possesses oxidative capacity which is easily deposited in air ways and results in oxidative damage and inflammation leading to obstruction of airways. Air way obstruction leads to decline in lung function test including peak expiratory flow rate (PEFR). Peak expiratory flow rate is a direct simple and reliable parameter for assessment of lung functions and helpful in measuring the obstruction of even smaller air ways ${ }^{3}$.

Several previous epidemiological studies have reported the occurrence of cardio vascular diseases with exposure to chemicals like Sulphur dioxide, carbon dioxide, nitric dioxide and PM emitted from the factories ${ }^{3,4}$. Air pollution causes the oxidative stress and damage to vascular endothelium and severe vasoconstriction ${ }^{3}$. Strong evidences are also available showing that elevation in physiological levels of neuro-transmitters like adrenaline, dopamine and serotonin are possible causes of sever vaso-constriction and potentially increase the systemic blood pressure due to exposure to industrial chemicals ${ }^{4}$. Various previous studies also documented that people working or living in the vicinity of chemical industries having more exposure to chemical fumes are at a greater risk of cardiopulmonary diseases ${ }^{5}$.Link between longterm exposure to air pollution and cardiovascular diseases is well established, however literature concerning effects on blood pressure is limited ${ }^{3}$.Numerous previous studies have already assessed the cardiopulmonary functions in subjects having exposure to chemicals and established its link with cardiac diseases but its impact on blood pressure still remains a question to be answered ${ }^{5}$. Furthermore, there is paucity of data showing the association of lung function parameters like PEFR and blood pressure in people who are exposed to industrial pollutants. This study was designed to assess the changes in PEFR and blood pressure in subjects having exposure to chemicals emitted from the industries in Faisalabad that is a hub of the industries. We also aimed to determine the association between the changes in blood pressure and PEFR in these male subjects.

The objectives of the were to determine the impact of duration of exposure to industrial chemical fumes on Peak Expiratory Flow Rate (PEFR) and blood pressure of the industrial workers and to find out the association between changes in blood pressure and PEFR due to exposure to industrial chemical fumes in these subjects.

\section{MATERIALS AND METHODS}

This cross-sectional study was performed at Aziz Fatimah Medical and Dental College, Faisalabad. Prior to study, ethical approval was taken from institutional ethical committee and informed consent was taken from the part-icipants. Free camp in the industrial area was arranged for three days in September 2020. Non-smokers male subjects aged 20 to 60 years working in chemical industries were included in the study. Thorough history was recorded in a predesigned proforma. Healthy non-smoker male subjects with exposure to chemicals for at least one year or more were included in the study. Hundred and fifty-one subjects who met inclusion criteria were enrolled in the study by convenient sampling technique. Subjects with known pulmonary diseases like asthma, tuberculosis, chronic obstructive pulmonary disease, cardiovascular diseases, smokers and female workers were excluded from the study. 
Weight in kilogram and height in centimeters were recorded using weight and BMI was calculated by dividing weight in kilogram by square of height in meters $(\mathrm{kg} / \mathrm{m} 2)$. PEFR values were recorded using Wrights handheld peak flow meter. For PEFR the participants were asked to blow out after deep inspiration, into the nozzle of peak expiratory flow meter, sealed tightly by lips. Three readings in Liters/Minute were taken from each participant and average was recorded for data analysis. Systolic and diastolic blood pressures in sitting posture were determined by auscultatory method using mercury sphygmomanometer after relaxing the subjects for at least 5 minutes. Sys-tolic readings were recorded on appearance of clear Korotkoff sounds and diastolic readings were recorded with disappearance of these sounds.

Data was statistically analyzed by SPSS version 22 . Age, height, weight, BMI, blood pressure and PEFR were expressed as mean \pm SD. Means of all parameters were compared by ANOVA. Multiple comparison done by Post hoc test (Tukey HSD). Association of PEFR with systolic and diastolic blood pressure was determined by regression analysis. A $p$ value $\leq 0.05$ was taken as significant.

\section{RESULTS}

This study comprised of 151 male participants having exposure to chemicals. Demographics of the study population are presented in the table 1 . Table 2 is indicating that the systolic and diastolic blood pressures were significantly raised in subjects with prolonged exposure to industrial chemical fumes. Significant differences were observed in mean systolic ( $\mathrm{p}$ value $=0.011$ ) and diastolic $(\mathrm{p}$ value $=0.037)$ blood pressure with respect to duration of exposure. On the other hand, PEFR value decline with increase in duration of exposure to industrial chemical fumes.

Post-hoc groups comparison (3 groups on the basis of duration of chemical exposure) of blood pressure and PEFR with respect to duration of chemical exposure shows statistically significant difference in mean systolic BP between the groups having exposure of 5 to 10 and greater than 10 years $(\mathrm{p}$ value $=0.014)$. However, concerning mean diastolic BP and PEFR, statistically significant differences were found in groups having exposure less than 5 and greater than 10 years with p values 0.029 and 0.001 respectively (Table 3 ).

Regression analysis shows significant negative association between diastolic blood pressure and PEFR ( $\mathrm{p}$ value $=0.003)$. Current results also show weak negative association between PEFR and systolic BP, however it was not statistically significant ( $\mathrm{p}=$ value 0.92$)$ (Table 4).

On analyzing the association between these parameters with duration of exposure, we found significant positive association of duration of exposure with systolic $(\beta=0.52, \mathrm{p}$ value $=0.000)$ diastolic blood pressure $(\beta=0.165, \mathrm{p}$ value $=$ 0.047). Beta coefficient of 0.52 and 0.165 indicates that increase in duration of exposure by one year will increase systolic and diastolic BP by 0.52 $0.165 \mathrm{mmHg}$.

Table 1: Descriptive of Study Population ( $n=151)$

\begin{tabular}{ll}
\hline Variables & Mean \pm SD \\
\hline Age (year) & $38.76 \pm 12.13$ \\
Height $(\mathrm{cm})$ & $170.07 \pm 12.05$ \\
Weight $(\mathrm{kg})$ & $78.12 \pm 12.79$ \\
$\begin{array}{l}\text { Body mass Index }\left(\mathrm{kg} / \mathrm{m}^{2}\right) \\
\text { Peak expiratory rate( PEFR) }\end{array}$ & $38.19 \pm 4.72$ \\
$\begin{array}{l}\text { (L/min) } \\
\text { Systolic Blood pressure } \\
\text { (mmHg) }\end{array}$ & $127.45 \pm 13.07$ \\
$\begin{array}{l}\text { Diastolic Blood pressure (mm } \\
\text { Hg) }\end{array}$ & $81.49 \pm 8.36$ \\
\hline
\end{tabular}


Table 2: Comparison of Blood Pressure and PEFR with Respect to Duration of Chemical Exposure

\begin{tabular}{llllll}
\hline Dependent variable & $\begin{array}{l}\text { Duration of } \\
\text { exposure in years }\end{array}$ & $\begin{array}{l}\mathbf{N} \\
(\mathbf{1 5 1})\end{array}$ & Mean & SD & p value* \\
\hline Systolic BP & Less than 5 & 62 & 124.92 & 11.682 & $0.011^{*}$ \\
$(\mathbf{m m}$ Hg) & $5-10$ & 34 & 125.29 & 12.119 & \\
& Greater than 10 & 55 & 131.64 & 14.242 & \\
Diastolic BP & Less than 5 & 62 & 131.64 & 14.242 & $0.037^{*}$ \\
$(\mathbf{m m}$ Hg) & 5-10 & 34 & 131.64 & 14.242 & \\
& Greater than 10 & 55 & 131.64 & 14.242 & \\
PEFR & Less than 5 & 62 & 366.90 & 89.185 & $0.001^{*}$ \\
(L/min) & 5-10 & 34 & 352.44 & 73.521 & \\
& Greater than 10 & 55 & 311.13 & 82.008 & \\
\hline
\end{tabular}

One-way ANOVA test was applied

${ }^{*} p$-value $\leq 0.05$ taken as significant, $P E F R=$ peak expiratory flow rate $B P=$ Blood Pressure

Table 3: Post-hoc comparison of Blood Pressure and PEFR with Respect to Duration of Chemical Exposure

\begin{tabular}{|c|c|c|c|c|c|}
\hline $\begin{array}{l}\text { Dependent } \\
\text { Variable }\end{array}$ & $\begin{array}{l}\text { Duration Exposure } \\
\text { Categories }\end{array}$ & $\begin{array}{l}\text { Duration Exposure } \\
\text { Categories }\end{array}$ & $\begin{array}{l}\text { Mean } \\
\text { Difference }\end{array}$ & Std. Error & p value \\
\hline \multirow[t]{3}{*}{$\begin{array}{l}\text { Systolic BP } \\
(\mathbf{m m ~ H g )}\end{array}$} & Less than 5 & $\begin{array}{l}5-10 \\
\text { Greater than } 10\end{array}$ & $\begin{array}{l}-.375 \\
-6.717\end{array}$ & $\begin{array}{l}2.725 \\
2.365\end{array}$ & $\begin{array}{l}0.990 \\
0.014^{*}\end{array}$ \\
\hline & $5-10$ & $\begin{array}{l}\text { Less than } 5 \\
\text { Greater than } 10\end{array}$ & $\begin{array}{l}.375 \\
-6.342\end{array}$ & $\begin{array}{l}2.725 \\
2.785\end{array}$ & $\begin{array}{l}0.990 \\
0.062\end{array}$ \\
\hline & Greater than 10 & $\begin{array}{l}\text { Less than } 5 \\
5-10\end{array}$ & $\begin{array}{l}6.717 \\
6.342\end{array}$ & $\begin{array}{l}2.365 \\
2.785\end{array}$ & $\begin{array}{l}0.014 * \\
0.062\end{array}$ \\
\hline \multirow[t]{3}{*}{$\begin{array}{l}\text { Diastolic BP } \\
(\mathrm{mm} \mathbf{H g})\end{array}$} & Less than 5 & $\begin{array}{l}5-10 \\
\text { Greater than } 10\end{array}$ & $\begin{array}{l}2.386 \\
-2.245\end{array}$ & $\begin{array}{l}1.757 \\
1.525\end{array}$ & $\begin{array}{l}0.366 \\
0.307\end{array}$ \\
\hline & $5-10$ & $\begin{array}{l}\text { Less than } 5 \\
\text { Greater than } 10\end{array}$ & $\begin{array}{l}-2.386 \\
-4.631\end{array}$ & $\begin{array}{l}1.757 \\
1.796\end{array}$ & $\begin{array}{l}0.366 \\
0.029 *\end{array}$ \\
\hline & Greater than 10 & $\begin{array}{l}\text { Less than } 5 \\
5-10\end{array}$ & $\begin{array}{l}2.245 \\
4.631\end{array}$ & $\begin{array}{l}1.525 \\
1.796\end{array}$ & $\begin{array}{l}0.307 \\
0.029 *\end{array}$ \\
\hline \multirow[t]{3}{*}{$\begin{array}{l}\text { PEFR } \\
(\mathrm{L} / \mathrm{min})\end{array}$} & Less than 5 & $\begin{array}{l}5-10 \\
\text { Greater than } 10\end{array}$ & $\begin{array}{l}14.462 \\
55.776\end{array}$ & $\begin{array}{l}17.775 \\
15.428\end{array}$ & $\begin{array}{l}0.695 \\
0.001 *\end{array}$ \\
\hline & $5-10$ & $\begin{array}{l}\text { Less than } 5 \\
\text { Greater than } 10\end{array}$ & $\begin{array}{l}-14.462 \\
41.314\end{array}$ & $\begin{array}{l}17.775 \\
18.171\end{array}$ & $\begin{array}{l}0.695 \\
0.063\end{array}$ \\
\hline & Greater than 10 & $\begin{array}{l}\text { Less than } 5 \\
5-10\end{array}$ & $\begin{array}{l}-55.776 \\
-41.314\end{array}$ & $\begin{array}{l}15.428 \\
18.171\end{array}$ & $\begin{array}{l}0.001 * \\
0.063\end{array}$ \\
\hline
\end{tabular}

Tukey test was applied

*p-value $<0.05$ was considered as statistically significant.

However, PEFR is negatively associated with duration of exposure with PEFR ( $\beta=-2.733$, $p$ value $0.001)$. Beta coefficient of -2.733 shows that an increase in duration of exposure by one year, will decrease PEFR by $2.733 \mathrm{~L} / \mathrm{min}$. 
Table 4: Regression Analysis between Blood Pressure and Peak Expiratory Flow Rate

\begin{tabular}{llll}
\hline $\begin{array}{l}\text { Dependent } \\
\text { Variables }\end{array}$ & $\begin{array}{l}\text { Beta } \\
\text { coefficient } \\
(\boldsymbol{\beta})\end{array}$ & $\begin{array}{l}\text { Standard } \\
\text { error } \\
(\mathrm{SE})\end{array}$ & $\begin{array}{l}\mathbf{p} \\
\text { value }\end{array}$ \\
\hline $\begin{array}{l}\text { Diastolic } \\
\text { blood }\end{array}$ & -2.469 & 0.822 & $0.003^{*}$ \\
$\begin{array}{l}\text { pressure } \\
(\mathbf{m m ~ H g})\end{array}$ & & & \\
\hline
\end{tabular}

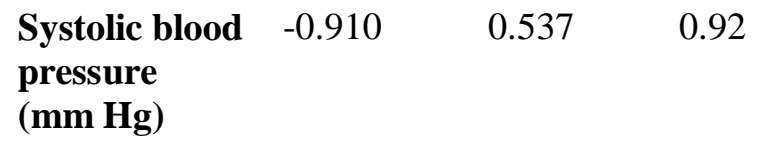

p-value $\leq 0.05$ taken as significant

$P E F R=$ peak expiratory flow rate

*PEFR is the independent variable

\section{DISCUSSION}

Environmental pollution due to increasing number of industries worldwide is a great public health concern. Fumes of noxious gases, PM and numerous other chemicals in atmosphere causes injurious effects on human body that affects the quality of life of these individuals ${ }^{1}$. This study was performed to highlight hazardous effects of industrial chemical fumes and PM on the heart and lungs, as lungs are in direct contact with the atmospheric air and are naturally first to bear the brunt of the atmospheric contamination. Inhalation of noxious gases with fine PM get deposited in the alveolar walls and bronchioles causing decrease in the elastic recoil of the lungs leading irreversible air flow limitation and compromised lung functions ${ }^{5}$. The current study determined the blood pressure and peak expiratory rate of the subjects having history of long-term exposure to chemical fumes emitted from the industries.

Baseline measurements of PEFR in the study population were $343.33 \mathrm{~L} / \mathrm{min}$ for men that were reduced with increase in duration of the exposure to chemical fumes emitted from the industries. These base line values are in accordance with
Table 5: Regression Analysis Between Blood Pressure(s), PEFR and Exposure Duration

\begin{tabular}{llll}
\hline $\begin{array}{l}\text { Dependent } \\
\text { Variables }\end{array}$ & $\begin{array}{l}\text { Beta } \\
\text { coefficient } \\
(\boldsymbol{\beta})\end{array}$ & $\begin{array}{l}\text { Standar } \\
\mathbf{d} \text { error } \\
(\mathbf{S E})\end{array}$ & $\begin{array}{l}\mathbf{p} \\
\text { value }\end{array}$ \\
\hline $\begin{array}{l}\text { Diastolic blood } \\
\text { pressure } \\
(\mathbf{m m} \mathrm{Hg})\end{array}$ & 0.165 & 0.082 & 0.047 \\
\hline
\end{tabular}

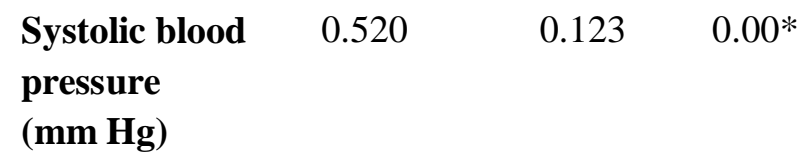

$\begin{array}{llll}\text { PEFR } & -2.733 & 0.833 & 0.00 *\end{array}$

(L/min)

*Exposure duration is the independent variable

PEFR $=$ Peak Expiratory Flow Rate

$p$-value $\leq 0.05$ taken as significant

another previous study conducted at Faisalabad by Komal et al that reported similar values for residents of Faisalabad ${ }^{6}$.

We noticed significant lower PEFR values in workers having exposure of chemicals for greater than 10 years as compared to worker having duration exposure less than 5 years. Regression analysis show significant negative impact of duration of exposure on PEFR. Beta coefficient of -2.733 shows that increase in duration of exposure by one year, will decreases PEFR by $2.733 \mathrm{~L} / \mathrm{min}$. Our findings are in accordance with study conducted in Hyderabad, India, that also observed decrease in PEFR values with increase in duration of exposure to chemical fumes ${ }^{5}$.

Current study found increase in diastolic blood pressure with increasing the duration of exposure to chemicals. On multiple comparison by post hoc test we found significant difference in mean diastolic blood pressure of subjects having exposure of less than five years and greater than 10 years. Comparatively higher blood pressure was 
noticed in subjects having exposure more than 10 years than with exposure less than 5 years. Our findings are further affirming by results of regression analysis showing positive relation of diastolic blood pressure with duration of exposure. Beta coefficient of 0.165 indicates that increase in duration of exposure by one year will increase diastolic BP by $0.165 \mathrm{mmHg}$. Our findings are inconsistent with the previous studies by Lina et al and Jacobs et $\mathrm{al}^{3,7}$. They documented negative correlation between diastolic blood pressure and increase in duration of exposure to PM in air pollution $^{3,7}$.

Current study found that systolic blood pressure is significantly increasing with increase in the duration of chemical exposure. Our results indicate that subjects having exposure of 10 years have significantly higher systolic blood pressure as compared to subjects having exposure between 5 to 10 years. These findings are further strengthened by the results of regression analysis showing positive impact of duration of exposure on systolic blood pressure.

Beta coefficient of 0.52 indicates that increase in duration of exposure by one year will increase systolic BP by $0.52 \mathrm{mmHg}$. Results of current study are justified by the results of previous study that reported the delayed increase in systolic blood pressure due to short term exposure to air pollution having $\mathrm{PM}^{8}$.Suggestive pathway for $\mathrm{PM}$ induced delayed increase in the systolic pressure is an adrenal stress response i.e. increased glucocorticoids due to activation of hypothalamic-pituitary-adrenal axis ${ }^{8}$. Our results are also in accordance with study conducted by Jacob et al, that demonstrated significant elevation in systolic blood pressure on exposure to air pollution ${ }^{7}$.Arterial stiffness and reduced elasticity due to exposure to ambient air pollution is another possible cause of elevation of systolic blood pressure ${ }^{9}$.Scheer et al did not find any association between systolic pressure and air pollution, however they found positive association between pulse pressure and air pollution and also observed arterial stiffness in vascular walls ${ }^{10}$. On the other hand, Lina et al documented decrease in systolic blood pressure with presence of high PM and other toxic substances in air $^{3}$.

There was a significant negative association between diastolic blood pressure and PEFR. However, no association was found between systolic blood pressure and PEFR values. No literature was found concerning association between these parameters that are being affected by air pollution and are the primary indicators for cardiopulmonary dysfunction. To the best of our knowledge this is the first study in Pakistan highlighting association between diastolic blood pressure and PEFR showing the strength of this study. This research will open new horizon for future researches on a broader scale to validate this association.

\section{Limitations}

We cannot infer causal association between the parameters due cross-sectional study design.

\section{CONCLUSION}

There was a decrease in PEFR value with increasing duration of exposure to industrial chemical fumes. Systolic and diastolic blood pressures were significantly raised in subjects with increase duration of chemical exposure. PEFR has significant negative association with Diastolic blood pressure. No correlation was found between PEFR and systolic blood pressure.

\section{Conflicts of interest}

The authors have no conflicts of interest to report.

\section{Contributors}

Dr. Shireen Jawed contributed to study design, data collection, manuscripts writing, revise and approve the article. Dr. Benash Altaf contributed to study design, manuscripts writing, revise and approve the 
article. Qaisar Suhail did the statistical analysis and result interpretation. Dr. Noor-i-Kiran Naeem and Dr. Farah Amir Ali contributed to study design, data collection, revise and approve the article. All authors are equally accountable for research work and data.

\section{REFERENCES}

29. Tóthová D. Respiratory Diseases in Children and Air Pollution - The Cost of - Illness Assessment in Ostrava City. Cent Eur J Public Policy.2020; 14(1): 43-56. https://doi.org/10.2478/cejpp-2020-0003

30. Kurt OK, Zhang J, Pinkerton KE. Pulmonary health effects of air pollution. Curr Opin Pulm Med. 2016; 22(2): 138-43. doi:10.1097/MCP.0000000000000248.

31. Mu L, Deng F, Tian L, Li Y, Swanson M, Ying J, et al. Peak Expiratory Flow, Breath Rate and Blood Pressure in Adults with Changes in Particulate Matter Air Pollution during the Beijing Olympics: A Panel Study. Environ Res. 2014; 133: 4-11.

32. Kim KW, Won YL, Ko KS, Heo KH, Chung YH. The effects of hazardous chemical exposure on cardiovascular disease in chemical products manufacturing workers. Toxicol Res. 2012; 28(4): 269-77. doi: 10.5487/TR.2012.28.4.269.

33. Padaki SK, Amrut D, Kokiwar P. Peak expiratory flow rate in asymptomatic male workers exposed to chemical fumes, in various industries of Hyderabad. Int J Med Res Health Sci. 2014; 3(4): 870-5.

34. Atta K, Zia S, Jabeen F. Impact of Anthropometric Parameters on Peak Expiratory Flow Rate. J Aziz Fatm Med Den College. 2019; 1(2): 63-6.

35. Jacobs L, Buczynska A, Walgraeve C, Delcloo A, Potgieter Vermaak S, Van Grieken R, et al. Acute changes in pulse pressure in relation to constituents of particulate air pollution in elderly persons. Environ Res. 2012; 117: 60-7. doi: 10.1016/j.envres.2012.05.003.

36. Fedak KM, Good N, Walker ES, Balmes J, Brook RD, Clark ML, et al. Acute Effects on Blood Pressure Following Controlled Exposure to Cookstove Air Pollution in the STOVES Study. J Am Heart Assoc. 2019; 8(14): e012246. doi: 10.1161/JAHA.119.012246.

37. Cai Y, Zhang B, Ke W, Feng B, Lin H, Xiao J, et al. Associations of Short-Term and Long-Term Exposure to Ambient Air Pollutants with Hypertension: A Systematic Review and Meta-Analysis. Hypertension.
2016; 68(1): 62-70. doi: 10.1161/HYPERTENSIONAHA.116.07218.

38. Scheers H, Nawrot TS, Nemery B, Casas L. Changing places to study short-term effects of air pollution on cardiovascular health: a panel study. Environ Health. 2018; 17(1): 80. doi: 10.1186/s12940-018-0425-7. 